\title{
Assessment of Relevant Physical Phenomena Controlling Thermal Performance of Nanofluids
}

\author{
Majid Bahrami* \\ University of Victoria, Victoria, British Columbia V8W 3P6, Canada \\ and \\ M. Michael Yovanovich $\ddagger$ and J. Richard Culham \\ University of Waterloo, Waterloo, Ontario N2L 3G1, Canada
}

DOI: $\underline{10.2514 / 1.28058}$

\begin{abstract}
This paper provides an overview of the important physical phenomena necessary for the determination of effective thermal conductivity of nanofluids. Through an investigation, a large degree of randomness and scatter has been observed in the experimental data published in the open literature. Given the inconsistency in these data, it is impossible to develop a comprehensive physical-based model that can predict all the trends. This also points out the need for a systematic approach in both experimental and theoretical studies. Upper and lower bounds are developed for steady-state conduction in stationary nanofluids. Comparisons between these bounds and the experimental data indicate that all the data (except for carbon nanotube data) lie between the lower and upper bounds.
\end{abstract}

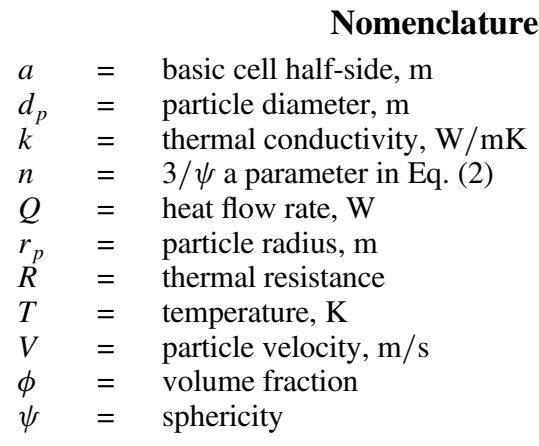

Subscripts

$e \quad=$ effective

$l=$ lower bound

$m=$ matrix, base fluid

$p=$ particle

$u \quad=\quad$ upper bound

\section{Introduction}

$\mathbf{T}$ HE significant growth in performance and functionality of microelectronics combined with a miniaturization trend in microelectromechanical systems (MEMS) have resulted in an unprecedented increase in heat loads that present a great challenge to thermal engineers. The novel concept of nanofluids shows promise to meet some of these challenges.

Nanofluids, a name coined by Choi [1], are liquid-particle laden mixtures consisting of solid nanoparticles, with sizes less than $100 \mathrm{~nm}$, suspended in a liquid, with solid volume fractions typically less than 4\%. Pioneer works of Masuda et al. [2], Artus [3], and

Received 27 September 2006; revision received 12 March 2007; accepted for publication 27 March 2007. Copyright $@ 2007$ by the American Institute of Aeronautics and Astronautics, Inc. All rights reserved. Copies of this paper may be made for personal or internal use, on condition that the copier pay the $\$ 10.00$ per-copy fee to the Copyright Clearance Center, Inc., 222 Rosewood Drive, Danvers, MA 01923; include the code 0887-8722/07 \$10.00 in correspondence with the CCC.

*Assistant Professor, Department of Mechanical Engineering; mbahrami@uvic.ca. Member AIAA.

†Professor Emeritus, Department of Mechanical Engineering; mmyov@ mhtlab.uwaterloo.ca. Fellow AIAA.

¥Associate Professor, Department of Mechanical Engineering; rix@ mhtlab.uwaterloo.ca.
Eastman et al. [4] introduced the thermal conductivity enhancement of nanofluids to the scientific community. Since then a large number of experimental and theoretical studies have been published by numerous research groups from all over the globe. This new class of heat transfer fluids has shown several attractive characteristics including the possibility of obtaining large enhancements (up to $40 \%$ ) in thermal conductivity compared with the base liquid [5], strong temperature dependent effects [6], reduced friction coefficient [7], and significant increases (threefold) in critical heat flux []. Choi et al. [9] tested a carbon nanotube-in-oil nanofluid and reported a dramatic enhancement in the effective thermal conductivity of the nanofluid (a factor of 2.5 at a volume fraction of $1 \%$ ). Pak and Cho [10] studied the convective heat transfer coefficient of nanofluids in cylindrical tubes. They [10] used $\gamma-\mathrm{Al}_{2} \mathrm{O}_{3}$ and $\mathrm{TiO}_{2}$ nanoparticles in water and showed that the Nusselt number of the nanofluid is higher than the base fluid. Furthermore, a new class of heat exchangers (using nanofluids) is being developed for medical applications including cancer therapy [11]. In addition, due to the small size of nanoparticles and small volume fraction, problems such as sedimentation, clogging, abrasion, and an increase in pressure drop become insignificant. Observed behavior in many cases cannot be explained via existing macroscopic models, indicating the need for new models that properly capture the features of nanofluids.

Presently, there are two methods for fabricating nanofluids:

1) In the two-step process, nanoparticles are first produced as a dry powder, typically by an inert-gas condensation method. The resulting nanoparticles are then dispersed into a fluid. This method may result in a large degree of nanoparticle agglomeration. On the other hand, the inert-gas condensation technique has already been scaled up to economically produce tonnage quantities of nanopowders [11].

2) The direct-evaporation technique [12] (single-step), synthesizes nanoparticles and disperses them into a fluid in a single step. A significant limitation to the application of this technique is that the liquid must have low vapor pressure, typically less than 1 torr. Also the quantities of nanofluids that can be produced via this directevaporation technique are much more limited than with the two-step method. Nanoparticle agglomeration is minimized as a result of flowing the liquid continuously. Moreover, nanofluids made using this method showed higher conductivity enhancement than the ones made by the two-step method.

When the dimensions of a system are reduced to the nanoscale, the thermal conductivity of the material will decrease due to the boundary scattering of the phonon and/or electrons [13]. It is intuitive that the thermal conductivity of the nanoparticle suspension be lower 
than that of the large particle suspension. However, measured effective thermal conductivity of nanofluids shows higher values than the values calculated by theoretical correlations such as Maxwell [14] and Hamilton-Crosser (HC) [15] even when the thermal conductivity of nanosized particles are taken as a bulk value.

A long list of physical phenomena has been proposed for explaining the experimentally observed enhancement of effective thermal conductivity of nanofluids, including the following: size and shape effects, agglomeration, clustering of particles, interfacial resistance, Brownian motion of nanoparticles resulting in microconvection, phonon dispersion, and liquid layering at the particle surface.

In this study, we focus only on the effective thermal conductivity of stationary nanofluids, that is, in the absence of the bulk flow and/or forced or natural convection. The paper is divided into three major parts: 1) a review of the theoretical models, 2) experimental investigations in the open literature, and 3) development of upper/ lower bounds for steady-state conduction in stationary nanofluids and comparing them with data. In the experimental part, important phenomena involved in the effective conductivity of nanofluids are discussed and the trends of the data reported are shown.

The objective of this paper is to provide an overview on the important physical phenomena involved in the effective thermal conductivity of nanofluids; and also show the level of scatter and complexity in the published data. The inconsistency seen in the data clearly shows the need for a systematic approach in both experimental and theoretical studies. It also illustrates that the development of a comprehensive model (that can explain all the trends) is a difficult task at the present time.

\section{Theoretical Models}

The existing models can be categorized more or less into two general groups [16]:

1) Static models assume stationary nanoparticles in the base fluid as a composite in which the thermal transport properties are predicted by conduction-based models such as Maxwell [14] and HamiltonCrosser [15], and so on.

2) Dynamic models are based on the premise that nanoparticles have lateral, random motion in the fluid. This motion is believed to be responsible for transporting energy directly (e.g., through collision between nanoparticles) or indirectly (e.g., microliquid convection, mixing) that enhances the transport of thermal energy.

The following provides a brief summary of theoretical models.

Using potential theory, Maxwell [14] developed the following effective medium theory for noncontacting spherical particles:

$$
k_{e, \text { Maxwell }}^{*}=\frac{k_{p}^{*}(1+2 \phi)+2(1-\phi)}{k_{p}^{*}(1-\phi)+(2+\phi)}
$$

where $k_{p}^{*}=k_{p} / k_{m}$ and $k_{e}^{*}=k_{e} / k_{m}$. Maxwell's model is valid for relatively small volume fractions. This model has been modified for particle geometry, boundary resistance, and coating [17].

Hamilton and Crosser [15] extended Maxwell's model to include nonspherical particles:

$$
k_{e, \mathrm{HC}}^{*}=\frac{k_{p}^{*}[1+(n-1) \phi]+(n-1)(1-\phi)}{k_{p}^{*}(1-\phi)+(n-1)+\phi}
$$

where $n=3 / \psi$ and $\psi$ is the sphericity defined as the ratio of the surface area of a sphere, with a volume equal to that of the particle, to the surface area of the particle ( $\psi=1$ for sphere). The parameter $n$ is 3 and 6 for spherical and cylindrical particles, respectively.

$\mathrm{Yu}$ and Choi $[18,19]$ modified the Maxwell and the HamiltonCrosser models for the effective thermal conductivity of solid/liquid suspensions to include the effect of solid layering. This approach postulates a solidlike layer of liquid on the nanoparticle surface which has a relatively high thermal conductivity compared with the liquid. It is known that liquid molecules close to a solid surface form layered, solidlike structures which may have much higher thermal conductivity compared with the bulk fluid. The existence of this solid layer leads to a larger effective volume fraction that can explain the thermal conductivity increase to a certain degree. $\mathrm{Yu}$ and Choi $[18,19]$ concluded that this ordered nanolayer may have an impact on nanofluid thermal conductivity when the particle diameter is less than $10 \mathrm{~nm}$. However, in many cases, a very thick unrealistic solid liquid layer must be assumed to explain the observed enhancement which is unrealistic. Also, temperature dependence of the thermal conductivity of nanofluids cannot be explained by solid layering.

Interfacial thermal resistance exists at the surface interface of liquid and particles. For phonon-based conductors, the interfacial thermal resistance, also known as the Kapitza effect, can arise from differences in the phonon spectra of the two phases, and from scattering at the interface between the phases [11]. The Kapitza effect may be neglected for large-grain sized materials at room temperature. However, for nanosized structures the interface resistance can play an important role in the overall heat transfer. This resistance will have a negative impact on the thermal conductivity of nanofluids.

In dynamic models, the Brownian motion [20] of the suspended nanoparticles is assumed to be responsible for the extra thermal conductivity enhancement. Based on Brownian motion theory, the random velocity of the particles is

$$
V \propto \frac{\sqrt{T}}{d_{p}^{1.5}}
$$

As can be seen in Eq. (3) the particle random velocity has a direct relationship with the square root of the temperature of the mixture and is inversely proportional to the size of the particles to the power 1.5. If the random velocity of the particles is assumed to be responsible for part of the thermal transport in nanofluids, Brownian motion acts in favor of the enhancement observed in nanofluids. The trends predicted by the Brownian motion are qualitatively consistent with the experimental observation in general, that is, the smaller the size of the particle and the higher the temperature of the nanofluid, the higher the conductivity enhancement. Different ideas have been put forward to explain how Brownian motion contributes to thermal transport, for example, single particle motion, particle-particle collisions, and microliquid convection [21-23]. The energy exchange in direct collisions of nanoparticles in nanofluids may result in an enhancement in the effective thermal conductivity. Moreover, thermal conductivity can be enhanced as a result of fluid movement (microconvection) caused by the Brownian motion of nanoparticles. These models, particularly microconvection, are questionable because they assume that the particles are at a temperature different from the liquid. No explanations have been given regarding the origin of this temperature difference. Keblinski et al. [24] (and later Prasher [25]) investigated the effect of the Brownian motion on thermal conductivity of nanofluids and concluded that the thermal diffusion is much faster than Brownian diffusion even for extremely small particles.

Clustering of nanoparticles can result in creating lower thermal resistance paths in the suspension. However, clustering may lead to agglomeration of solids which in turn causes settling down of particles, having a negative effect of conductivity of the suspension. According to Keblinski et al. [24], the percolation threshold for random dispersions is on the order of $15 \%$ volume fraction. This rules out the thermal conductivity enhancement of nanofluids in lower volume fractions $(\phi<5 \%)$. Another possibility pointed out by Keblinski et al. [24] is the situation where particles are not in contact, but are within a specific distance (called liquid-mediated) allowing rapid heat flow between them.

Performing an order-of-magnitude analysis, Prasher [25] ruled out other possible mechanisms, and concluded that the convection caused by the Brownian motion is primarily responsible for the enhancement in the thermal conductivity of nanofluids. Prasher [25], following Koo and Kleinstreuer [26], developed a convectiveconductive model based on the convection caused by the Brownian motion of nanoparticles and showed good agreement with experimental data collected by others. His model [25], however, requires two fitting parameters which have relatively large ranges and must be known a priori. Recently, Prasher [27] studied the effects 
of multiple and dependent elastic scattering of phonons on transport phenomena in nanofluids. He [27] showed that the multiple scattering primarily affects the velocity and density of states of phonons and dependent scattering primarily affects the mean free path of phonons. Moreover, both effects increase with increasing the volume fraction of nanofluids.

Wang et al. [16] proposed a numerical model for evaluating the contribution of particle Brownian motion coupled with interparticle electrostatic potential to the thermal energy transport in nanofluids. Their model predicts qualitatively the trends of the conductivity dependences on particle size, volume fraction, and temperature. They [16] reported that two additional chemical factors, that is, particle zeta potential and Debye screening length, have strong effects on the thermal conductivity of nanofluids.

In conclusion, the existing models cannot predict the trends observed in nanofluids. The answer to the question of which phenomena are responsible for the conductivity enhancement in nanofluids is still the focus of heated debate in the scientific community.

\section{Bounds of Conduction}

In this section upper and lower bounds for steady-state heat conduction in liquid-particle mixtures are developed and compared with data. Elrod [28] first introduced these bounds for systems in which conduction is the only mode of heat transfer. The bounds set the limits for the conduction heat transfer in the system. Therefore, the actual thermal conductivity lies between the bounds. Often the geometric mean $k_{\text {geometric }}=\sqrt{k_{u} k_{l}}$ of the bounds provides a good estimate of the effective thermal conductivity of the system.

The mixture is considered as a large number of cells that can be represented by a basic cell, that is, a spherical particle in a cube; see Figs. $\underline{1}$ and $\underline{2}$. Thus, the mixture is modeled as identical particles dispersed throughout a continuous medium. Thermal conductivities of the particles and the base fluid are constant, isotropic $k_{p}$ and $k_{m}$, respectively. The boundary conditions of the cell are determined from symmetry and are shown in Fig. 1. The four faces of the cell parallel to the direction of heat flow are adiabatic. The other two faces are isothermal. Heat enters the cell from the top face and exits through the bottom boundary.

\section{A. Lower Bound: Parallel Adiabats}

A lower bound for the effective conductivity of the basic cell can be established by assuming adiabats parallel to the direction of heat flow; see Fig. 1. Usually particles have much higher thermal conductivities compared with base liquids, that is, $k_{p} / k_{m} \gg 1$, thus the thermal resistance of particles may be ignored. In other words, particles can be considered isothermal. This assumption may result in slightly higher values for the conduction bounds, but it will not effect our analysis because we want to establish the bounds for the effective

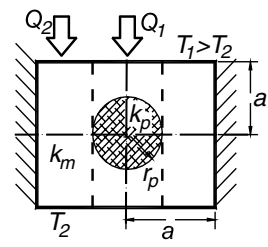

Fig. 1 Spherical particle in cubic cell, lower bound: parallel adiabats.

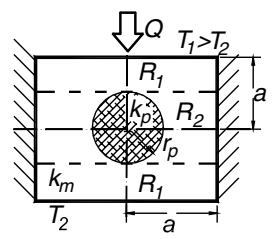

Fig. 2 Spherical particle in cubic cell, upper bound: perpendicular isotherms. conductivity. It is also a convenient assumption and simplifies the final results.

As shown in Fig. 1, there are two parallel paths in which heat flows $Q_{1}$ and $Q_{2}$ are being transferred. For a particle of radius $r_{p}$ in a cubic cell with side dimension $2 a$ after some algebra and normalizing, we find

$$
Q_{1}=\frac{\pi \Delta T k_{m} r_{p}^{2}}{a} \int_{0}^{1} \frac{\zeta d \zeta}{1-\phi^{*} \sqrt{1-\zeta^{2}}}
$$

where $\Delta T=T_{1}-T_{2} ; \phi^{*}=r_{p} / a$ can be related to the mixture volume fraction

$$
\phi^{*}=\frac{r_{p}}{a}=\left(\frac{6}{\pi} \phi\right)^{1 / 3}
$$

The integral in Eq. (4) has a closed form solution

$$
Q_{1}=-\pi \Delta T k_{m} r_{p} \frac{\phi^{*}+\ln \left(1-\phi^{*}\right)}{\phi^{*}}
$$

The heat transfer through the base fluid can be found from

$$
Q_{2}=2 a k_{m} \Delta T\left(1-\frac{\pi}{4} \phi^{* 2}\right)
$$

Combining $Q_{1}$ and $Q_{2}$, the total heat transfer in the unit cell can be found. The effective lower bound for conduction becomes

$$
k_{l}^{*}=\frac{k_{l}}{k_{m}}=1-\frac{\pi}{4} \phi^{* 2}-\frac{\pi}{2} \phi^{*}-\frac{\pi}{2} \ln \left(1-\phi^{*}\right)
$$

Note that at the limit where $\phi^{*}=0$ (no particles), Eq. ( $\underline{8}$ ) yields $k_{l}^{*}=1$ as expected.

\section{B. Upper Bound: Perpendicular Isotherms}

An upper bound for the effective conductivity of the basic cell can be established by assuming isotherms perpendicular to the direction of heat flow through the cell; see Fig. 2. With an approach similar to the lower bound, the upper bound on effective thermal conductivity for the unit cell can be found:

$$
k_{u}^{*}=\frac{k_{u}}{k_{m}}=\frac{1}{1-\phi^{*}}
$$

where at the limit $\phi^{*}=0$, Eq. (9) yields $k_{u}^{*}=1$. Applying the same assumption, $k_{p} / k_{m} \gg 1$, the Maxwell model, Eq. (1), reduces to

$$
\left.k_{e, \text { Maxwell }}^{*}\right|_{k_{p} / k_{m} \gg 1}=\frac{1+2 \phi}{1-\phi}
$$

Note that the upper/lower bounds and the Maxwell model are not sensitive to the conductivity ratio $k_{p}^{*}=k_{p} / k_{m}$ when $k_{p}^{*}$ is about 40 and higher; they approach the isothermal particle case which is being used in the analysis. If the bulk thermal conductivity values can be assumed for the nanoparticles, the thermal conductivity ratio is about 40 or higher for most of the nanofluid data.

\section{Comparison with Data}

Figures $\underline{3}-\underline{6}$ show a comparison between Maxwell's model Eq. (10) and the upper/lower bounds of conduction, that is, Eqs. (8) and (9) with experimental data. The data are collected from several sources and categorized based on the nanoparticle material and the base fluid which include $\mathrm{CuO}$ and $\mathrm{Al}_{2} \mathrm{O}_{3}$ dispersed in ethylene glycol and water over a range of the volume fraction.

As can be seen in Eqs. (8-10), the absolute size of the particles does not have a direct effect on the effective conductivity in conduction-based models; it appears in the volume fraction. However, the nanoparticle diameters (as reported) are listed in Figs. 3-6 to show the range of particle sizes used in the tests.

The data show a large scatter, with some level of conductivity enhancement when compared with the Maxwell's model. It is 


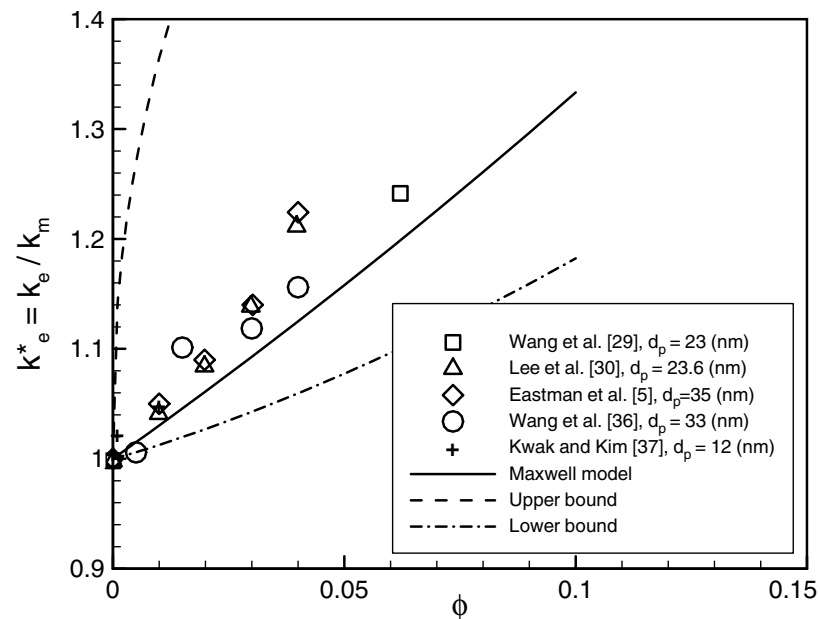

Fig. $3 \mathrm{CuO}$ nanoparticles in ethylene glycol; data from various sources.

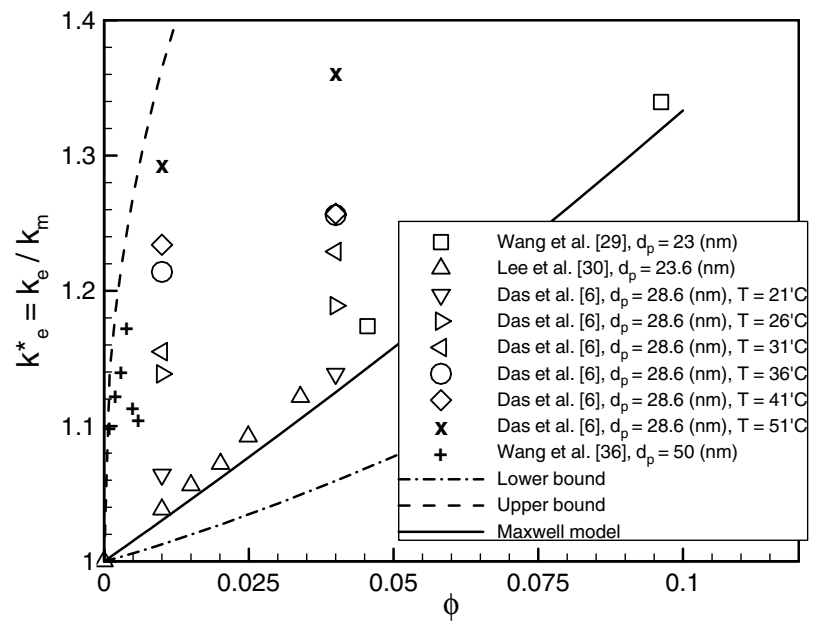

Fig. $4 \mathrm{CuO}$ nanoparticles in water; data from various sources.

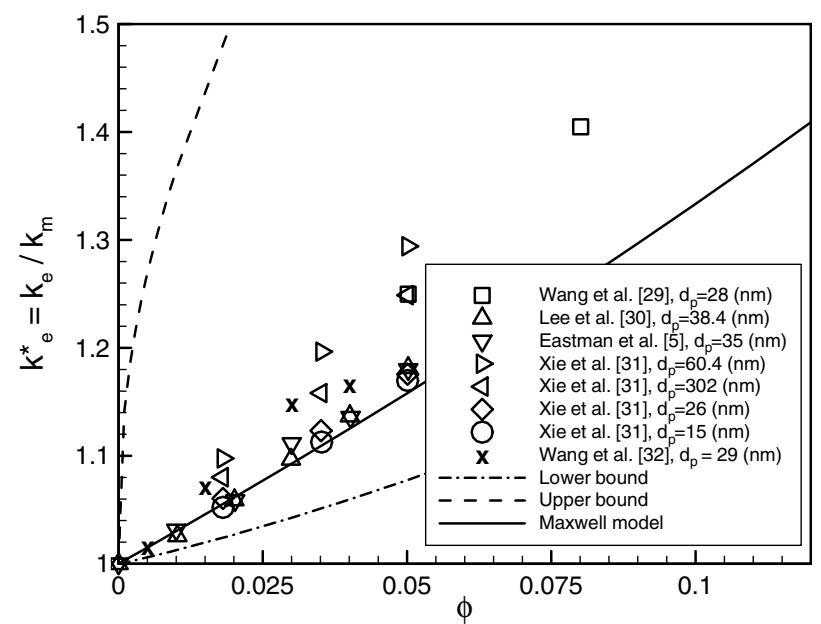

Fig. 5 Aluminum oxide nanoparticles in ethylene glycol; data from various sources.

interesting to observe that all the data lie between the lower and upper bounds of conduction.

\section{Trends in Experimental Data}

Much experimental research has been performed to study the thermal conductivity enhancement of nanofluid mixtures including nanoparticles $\mathrm{Cu}, \mathrm{Fe}, \mathrm{CuO}, \mathrm{CeO}_{2}, \mathrm{Al}_{2} \mathrm{O}_{3}, \mathrm{ZnO}, \mathrm{TiO}_{2}$ in base fluids such as water, ethylene glycol, and oils. The existing experimental data are collected and summarized in this section. Tables 1 and 2 list reference, particle material, particle size, volume fraction $\phi$, $\bar{b}$ ase fluid, and the maximum conductivity enhancement measured for nanofluids. We also included major findings and important trends reported by researchers in these tables. For example, the second row of Table 1 reads as follows: Lee et al. [30] used $\mathrm{Al}_{2} \mathrm{O}_{3}$ and $\mathrm{CuO}$ nanoparticles of diameters 38.4 and $23 . \overline{6}(\mathrm{~nm})$ dispersed in water $\left(\mathrm{H}_{2} \mathrm{O}\right)$ and ethylene glycol (EG), made suspensions with volume fractions within the range $0 \leq \phi \leq 5 \%$, maximum thermal conductivity enhancement measured with $\mathrm{Al}_{2} \mathrm{O}_{3}-\mathrm{H}_{2} \mathrm{O}$ and $\mathrm{CuO}-\mathrm{H}_{2} \mathrm{O}$ were 10 and $12 \%$, respectively.

There are two popular techniques for measuring effective thermal conductivity of nanofluids:

1) The transient hot-wire (THW) method [38] involves a wire suspended symmetrically in a liquid in a vertical cylindrical container. The wire serves as both a heating element and a temperature sensor. The THW method is fast and eliminates natural convection effects, this method has been used by a majority of researchers.

2) The steady-state method (SSM), used by $[29,32]$, is based on steady-state, one-dimensional heat transfer from an electrical heater to a cold plate through two calibrated heat flux meters. To avoid bulk fluid movement due to natural convection forces, the heat transfer direction should be from top to bottom of the sample.

Czarnetzki and Roetzel [39] introduced an oscillation technique to measure thermal diffusivity and thermal conductivity of liquids. In this technique, the liquid specimen is a slab that is bounded above and below by a reference material. Using two Peltier elements, mounted on the outer surfaces of the reference layers, temperature oscillations are generated which then propagate through the reference layers into the specimen. The thermal diffusivity and then thermal conductivity of the sample can be deduced by measuring and evaluating the amplitude attenuation and/or the phase shift between fundamental temperature oscillations at the surface of the liquid specimen at a known position inside the specimen. To the authors' knowledge, the method of [39] has not been used to measure the thermal conductivity of nanofluids. Another thermal conductivity measurement technique is the 3-omega method. 3-Omega is a frequency-based measurement technique to minimize extraneous losses associated with measuring thermal conductivity and specific heat in thin films and thin wires where the fin effect associated with thermocouple measurements and radiation losses can influence the results. Although the method could be used for nanofluids, the inherently higher resistance associated with fluids (as opposed to solids) does not warrant the use of the 3omega method.

In the following subsections, major trends observed in experimental studies are discussed and when possible the data are shown.

\section{A. Effect of Nanoparticles Material}

Wang et al. [32] measured thermal conductivity of different nanoparticles including $\mathrm{Al}_{2} \mathrm{O}_{3}, \mathrm{ZnO}, \mathrm{CuO}, \mathrm{CeO}_{2}$, and $\mathrm{Fe}_{2} \mathrm{O}_{3}$ suspended in transformer oil and ethylene glycol. A steady-state method was employed. They also did not use surfactant in their samples. Figure 7 shows a comparison between the data of Wang et al. [32] and Maxwell's model and the upper/lower bounds. It is expected to see the highest conductivity enhancement for the nanoparticles that have the highest thermal conductivity (say $\mathrm{CuO}$ ) and/or the smallest particle size, that is, $\mathrm{Fe}_{2} \mathrm{O}_{3}$; see Table 1 . However, as shown in Fig. 7, none of the above is true in Wang et al. [32] data. The highest enhancement belongs to $\mathrm{ZnO}$ nanoparticles which have the largest mean size of nanoparticles.

Eastman et al. [5] showed that higher thermal conductivity particles result in higher thermal enhancement of the suspension, that is, the $\mathrm{Cu}$-EG nanofluid had higher thermal conductivity enhancement compared with $\mathrm{CuO}-\mathrm{EG}$ and $\mathrm{Al}_{2} \mathrm{O}_{3}-\mathrm{EG}$ nanofluids. It should be mentioned that Eastman et al. [] ] employed a single-step procedure to fabricate their nanofluid samples. 
Table 1 Summary of experimental data: linear increase in conductivity enhancement with volume fraction

\begin{tabular}{|c|c|c|c|c|c|c|}
\hline Ref. & Particle & $d_{p}, \mathrm{~nm}$ & $\phi$ & \multicolumn{2}{|c|}{ Base fluid and $\left.k_{e}^{*}\right|_{\max } \%$} & Notes \\
\hline [29] & $\begin{array}{c}\mathrm{Al}_{2} \mathrm{O}_{3} \\
\mathrm{CuO}\end{array}$ & $\begin{array}{l}28 \\
23\end{array}$ & $0 \leq \phi \leq 15 \%$ & $\begin{array}{c}\mathrm{H}_{2} \mathrm{O} \\
\text { EG } \\
\text { Engine oil } \\
\text { Vacuum pump fluid }\end{array}$ & $\begin{array}{l}15 \\
40 \\
30 \\
20\end{array}$ & $\begin{array}{c}\text { Viscosity } \nearrow \text { as } \phi \nearrow k_{e}^{*} \text { linear with } \phi \mathrm{SSM}, \\
\text { two-step room } T, 3 \% \text { error }\end{array}$ \\
\hline$[\underline{30]}$ & $\begin{array}{l}\mathrm{Al}_{2} \mathrm{O}_{3} \\
\mathrm{CuO}\end{array}$ & $\begin{array}{l}38.4 \\
23.6\end{array}$ & $0 \leq \phi \leq 5 \%$ & $\begin{array}{c}\mathrm{Al}_{2} \mathrm{O}_{3} \\
10 \\
18\end{array}$ & $\begin{array}{c}\mathrm{CuO} \\
12 \\
22\end{array}$ & $\begin{array}{c}k_{e}^{*} \text { linear with } \phi \text { THW, two-step room } T, \\
1.5 \% \text { error } k_{e}^{*} \nearrow \text { as } d_{p} \searrow\end{array}$ \\
\hline [5] & $\begin{array}{c}\mathrm{Al}_{2} \mathrm{O}_{3} \\
\mathrm{Cu} \\
\mathrm{CuO}\end{array}$ & $\begin{array}{l}35 \\
10 \\
35\end{array}$ & $\begin{array}{c}0 \leq \phi \leq 5 \% \\
0 \leq \phi \leq 0.5 \% \\
0 \leq \phi \leq 5 \%\end{array}$ & $\begin{array}{cc} & \mathrm{EG} \\
\mathrm{Cu} & 40 \\
\mathrm{CuO} & 22 \\
\mathrm{Al}_{2} \mathrm{O}_{3} & 18\end{array}$ & & $\begin{array}{c}k_{e}^{*} \text { linear with } \phi \mathrm{THW}, \text { one-step room } T, \\
1.5 \% \text { error higher } k_{p} \text { higher } k_{e}\end{array}$ \\
\hline [31] & $\mathrm{Al}_{2} \mathrm{O}_{3}$ & $\begin{array}{l}15 \\
26 \\
60.4 \\
302\end{array}$ & $0 \leq \phi \leq 5 \%$ & $\begin{array}{c}d_{p}=60(\mathrm{~nm}) \\
\mathrm{EG} \\
\mathrm{H}_{2} \mathrm{O} \\
\text { Pump oil }\end{array}$ & $\begin{array}{l}31 \\
21 \\
39\end{array}$ & $\begin{array}{c}k_{e}^{*} \text { linear with } \phi \mathrm{THW}, \text { two-step optimum } d_{p} \\
\text { for } k_{e}^{*} k_{e}^{*} \searrow \text { as } p \mathrm{H} \nearrow k_{e}^{*} \nearrow \text { as } k_{p} \searrow\end{array}$ \\
\hline [6] & $\begin{array}{c}\mathrm{Al}_{2} \mathrm{O}_{3} \\
\mathrm{CuO}\end{array}$ & $\begin{array}{l}38.4 \\
28.6\end{array}$ & $0 \leq \phi \leq 4 \%$ & $\begin{array}{l}\mathrm{H}_{2} \mathrm{O} @ 51^{\circ} \mathrm{C} \\
\mathrm{Al}_{2} \mathrm{O}_{3} \\
\mathrm{CuO}\end{array}$ & $\begin{array}{l}25 \\
35\end{array}$ & $\begin{array}{c}k_{e}^{*} \text { linear with } \phi \text { variable flux test, two-step } \\
21 \leq T \leq 51^{\circ} \mathrm{C} d\left(k_{e} / k_{m}\right) / d T \nearrow \text { as } \phi \nearrow k_{e}^{*} \nearrow \text { as } T\end{array}$ \\
\hline [32] & $\begin{array}{c}\mathrm{Al}_{2} \mathrm{O}_{3} \\
\mathrm{CeO}_{2} \\
\mathrm{TiO}_{2} \\
\mathrm{CuO} \\
\mathrm{Fe}_{2} \mathrm{O}_{3} \\
\mathrm{ZnO}\end{array}$ & $\begin{array}{l}29 \\
29 \\
40 \\
33 \\
28 \\
56\end{array}$ & $0 \leq \phi \leq 4 \%$ & EG & 20 & $k_{e}^{*}$ linear with $\phi \mathrm{SSM}$ no surfactant room $T$ \\
\hline$[\underline{33}]$ & $\mathrm{Au}$ & $\begin{array}{l}10-20 \\
60-80\end{array}$ & $0 \leq \phi \leq 0.01 \%$ & $\begin{array}{l}\text { Thiolate } \\
\text { Citrate }\end{array}$ & $\begin{array}{c}9 \\
8.5\end{array}$ & $\begin{array}{c}k_{e}^{*} \text { linear with } \phi \text { variable flux test, two-step } 30 \leq T \leq 60^{\circ} \mathrm{C} \\
\text { size effect dominates } k_{e}^{*} \nearrow \text { as } T \nearrow\end{array}$ \\
\hline
\end{tabular}

Table 2 Summary of experimental data: nonlinear increase in conductivity enhancement with volume fraction

\begin{tabular}{|c|c|c|c|c|c|c|}
\hline Ref. & Particle & $d_{p}, \mathrm{~nm}$ & $\phi$ & \multicolumn{2}{|c|}{ Base fluid and $\left.k^{*}\right|_{\max } \%$} & Notes \\
\hline [34] & $\begin{array}{l}\mathrm{TiO}_{2} \text { spherical } \\
\mathrm{TiO}_{2} \text { cylindrical }\end{array}$ & $\begin{array}{c}15 \\
10 \times 40\end{array}$ & $0 \leq \phi \leq 5 \%$ & $\begin{array}{c}\mathrm{H}_{2} \mathrm{O} \\
\text { Spherical } \\
\text { Cylindrical }\end{array}$ & $\begin{array}{l}30 \\
33\end{array}$ & $k_{e}^{*}$ not linear $\phi$ THW, two-step, room $T$ \\
\hline$[\underline{35}]$ & $\mathrm{Fe}$ & $10(7.6)$ & $0 \leq \phi \leq 0.6 \%$ & EG & 18 & $\begin{array}{c}k_{e}^{*} \text { not linear } \phi \text { THW, two-step, room } T k_{e}^{*} \nearrow \text { as sonication. } \\
t \nearrow \text { higher } k_{p} \neq \text { higher } k_{e}\end{array}$ \\
\hline$[\underline{36}]$ & $\mathrm{CuO}$ & 50 & $0 \leq \phi \leq 0.6 \%$ & $\mathrm{H}_{2} \mathrm{O}$ & 17 & $k_{e}^{*}$ not linear $\phi$ quasisteady state room $T$ \\
\hline [9] & Carbon nanotube & $25 \times 50,000$ & $0 \leq \phi \leq 1 \%$ & $\alpha$-olefin & 250 & $k_{e}^{*}$ not linear $\phi$ THW, two-step room $T$ \\
\hline [37] & $\mathrm{CuO}$ & 12 & $0 \leq \phi \leq 1 \%$ & EG & 6 & $\begin{array}{c}k_{e}^{*} \text { not linear } \phi \text { THW, two-step optimum sonication time room } T, \\
\text { prolate spheroid }\end{array}$ \\
\hline
\end{tabular}

\section{B. Shape Effect}

Murshed et al. [34] measured the effective thermal conductivity of rod shapes $10 \times 4 \overline{0} \mathrm{~nm}$ (diameter by length) and spherical shapes of $15 \mathrm{~nm} \mathrm{TiO}_{2}$ nanoparticles in deionized water. A transient hot-wire apparatus was used for the thermal conductivity measurements. As shown in Fig. 8, the cylindrical particles present a higher enhancement which is consistent with theoretical prediction, that is, the Hamilton-Crosser [15] model. Their experiments [34] also showed a nonlinear relationship between the thermal conductivity and volume fraction at lower volumetric loading $(0.005-0.02)$ and a linear relationship at higher volumetric loading (0.02-0.05). They attributed this trend to the influence of the cetyltrimethylammonium bromide surfactant and long time $(8-10 \mathrm{~h})$ of sonication, and hydrophobic surface forces in the nanofluids.

\section{Temperature Effect}

Das et al. [6] measured effective thermal conductivities of $\mathrm{Al}_{2} \mathrm{O}_{3}$ and $\mathrm{CuO}$ nanoparticles in water when the mixture temperature was varied between 21 to $51^{\circ} \mathrm{C}$. A temperature oscillation technique has been used for the conductivity measurements with a maximum error

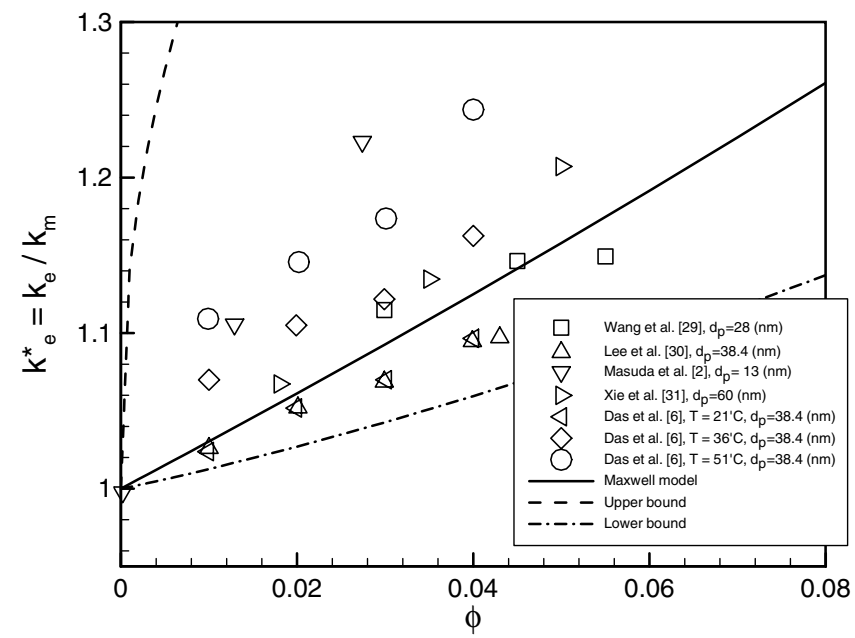

Fig. 6 Aluminum oxide nanoparticles in water; data from various sources. 


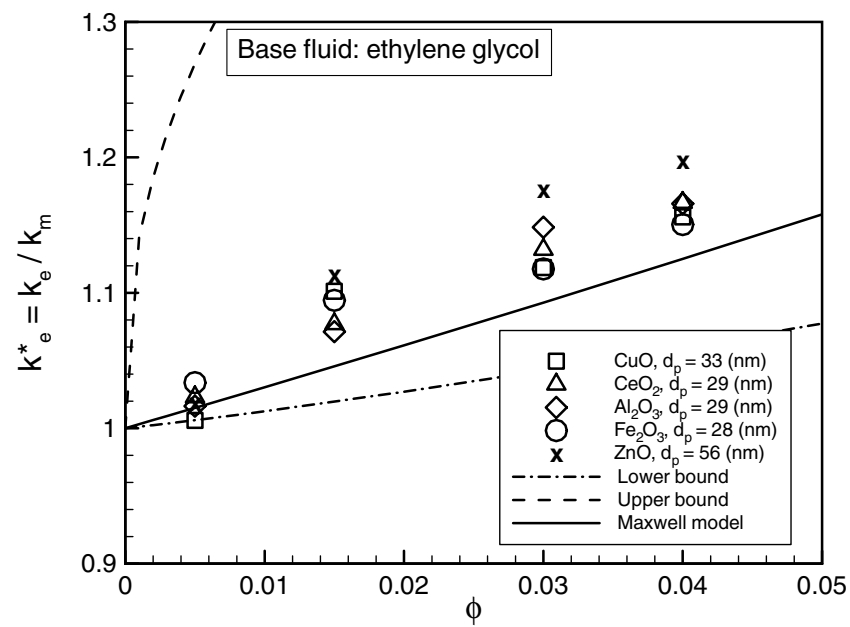

Fig. 7 Effect of nanoparticle material on effective thermal conductivity; data [32].

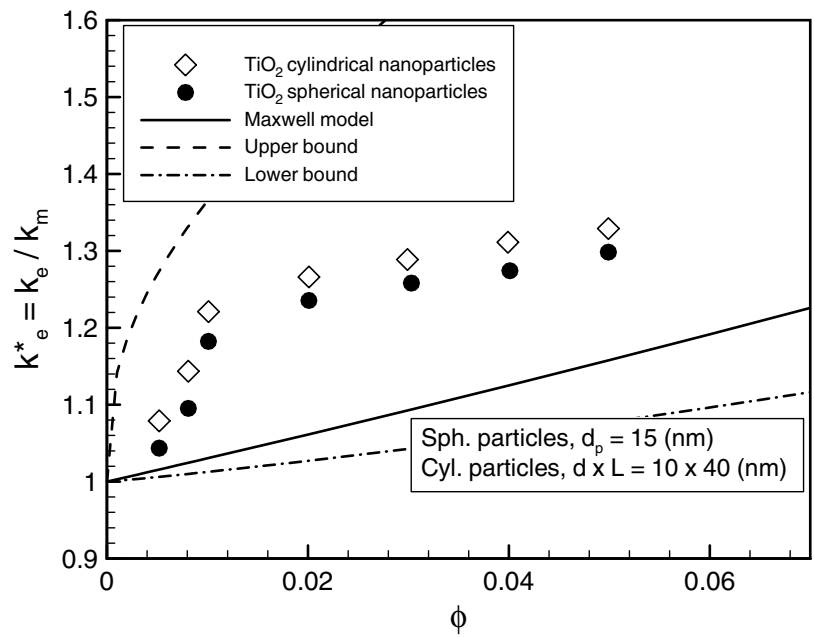

Fig. 8 Shape effect: cylindrical and spherical $\mathrm{TiO}_{2}$ nanoparticles in deionized water; data from Murshed et al. [34].

on the order of $7 \%$ at $50^{\circ} \mathrm{C}$. They reported a two- to fourfold thermal conductivity enhancement of nanofluids over a temperature range of 21 to $51{ }^{\circ} \mathrm{C}$. Also it has been observed that nanofluids containing smaller $\mathrm{CuO}$ particles show more enhancement of conductivity with temperature; see Figs. $\underline{9}$ and $\underline{10}$.

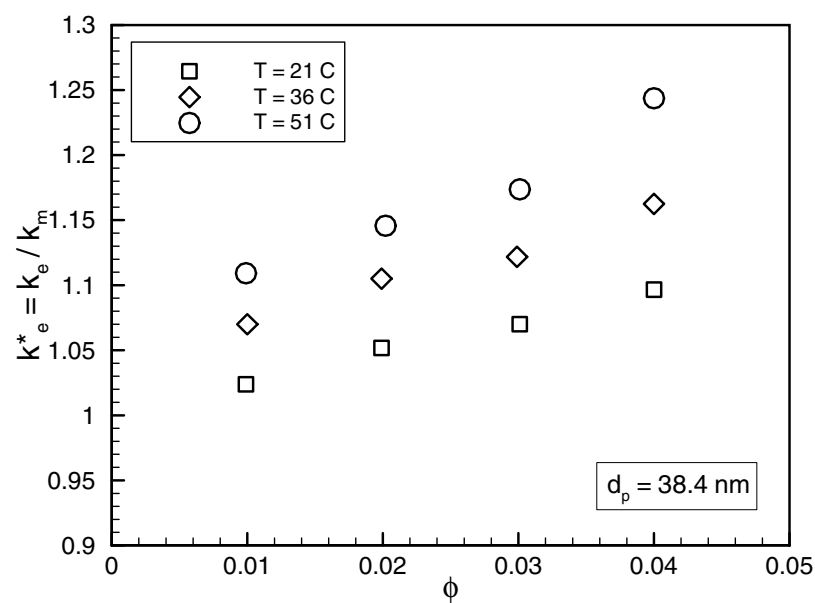

Fig. 9 Temperature effect: alumina-water nanofluid; data from Das et al. [6].

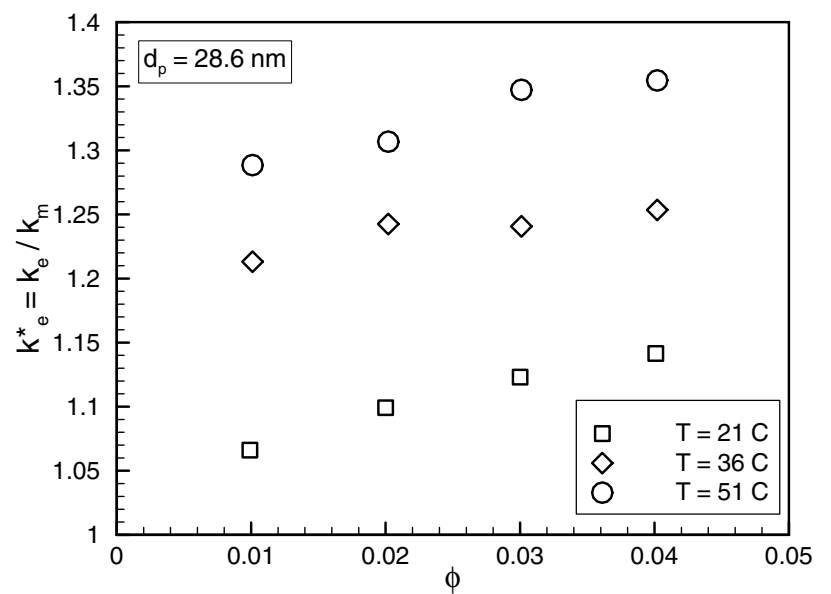

Fig. 10 Temperature effect: copper-oxide-water nanofluid; data from Das et al. [6].

\section{Effect of Sonication Time}

Kwak and Kim [37] studied the rheological properties and thermal conductivity enhancement of $\mathrm{CuO}$-ethylene glycol nanofluids with a particle size of 10-30 nm. Using transmission electron microscopy (TEM) images, they observed that individual $\mathrm{CuO}$ particles were the shape of prolate spheroid of the aspect ratio of 3 , and most of the particles were under aggregated states even after sonication for a prolonged period. To disperse particles, sonication was used with an ultrasound generator $(20 \mathrm{kHz}, 100 \mathrm{~W})$. It was found that if the duration of sonication was too long particles get coalesced again. To determine the optimum duration of sonication, they varied the duration from 1 to $30 \mathrm{~h}$ and measured the average size of particles as shown in Fig. 11. They concluded that the optimum duration time was $9 \mathrm{~h}$ and the average value was approximately $60 \mathrm{~nm}$.

Hong et al. [35] reported that the sonication (with high-powered pulses) resulted in an improvement in the effective thermal conductivity of nanofluid. Fe-ethylene glycol nanofluids were tested. Thermal conductivity of the nanofluids was measured using a transient hot-wire method. They measured thermal conductivity of nanofluids while changing the sonication time from 10 up to $70 \mathrm{~min}$. As shown in Fig. 12, the thermal conductivity increased nonlinearly with the sonication time.

\section{E. Particle Size Effect}

Xie et al. [31] also measured the effective thermal conductivity of nanofluids $\left(\overline{\mathrm{Al}}_{2} \mathrm{O}_{3}\right.$ in ethylene glycol) with different nanoparticle sizes. They reported an almost linear increase in conductivity with the volume fraction, but the rates of the enhanced ratios to the volume

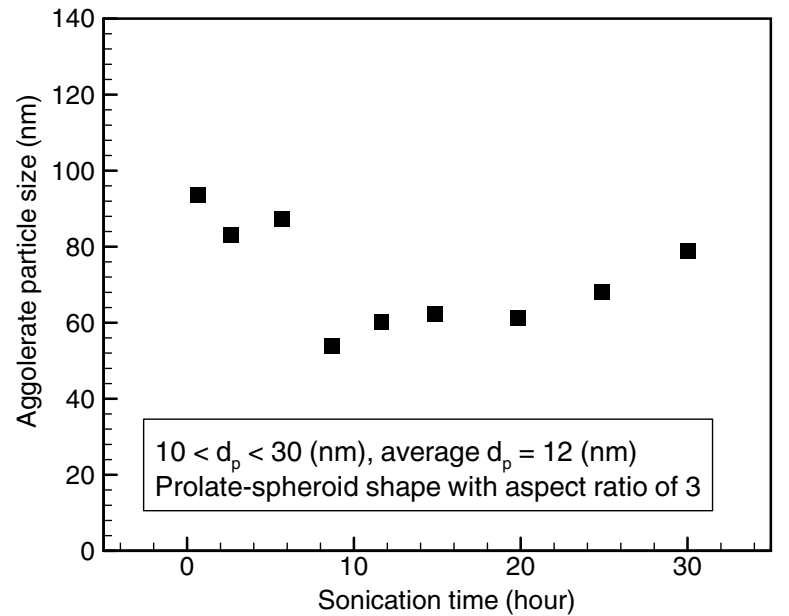

Fig. 11 Effect of sonication time on average size of $\mathrm{CuO}$ nanoparticle; data from [37]. 


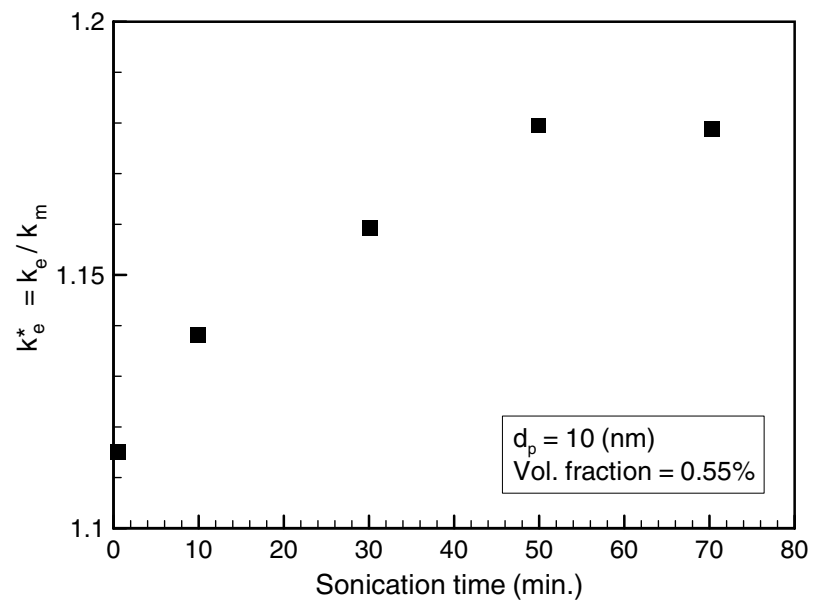

Fig. 12 Effect of sonication time on effective thermal conductivity of $\mathrm{Fe}$ nanoparticles in ethylene glycol; data from Hong et al. [35].

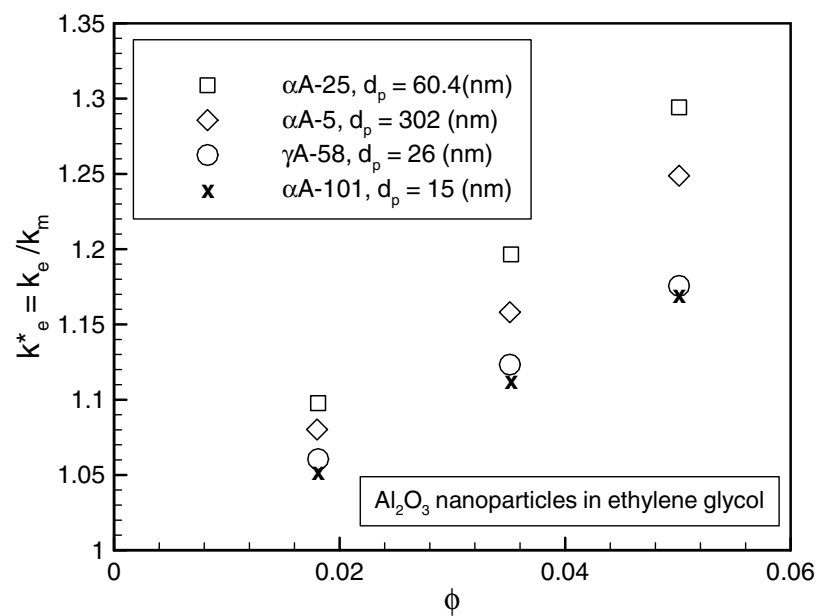

Fig. 13 Thermal conductivity enhancement in nanofluids with different particle sizes; data from Xie et al. [31].

fraction depended on the dispersed nanoparticles. They stated that the enhancements of the thermal conductivities were dependent on specific surface area (SSA) and the mean free path of nanoparticles and the base fluid. The data do not indicate the highest enhancement for the smallest size nanoparticles as it was expected; see Fig. 13. Xie et al. [31] concluded that the conductivity enhancement was thoroughly different from the traditional suspensions with $\mu \mathrm{m}$ or $\mathrm{mm}$ size particles dispersed in a fluid.

\section{F. Other Effects}

Xie et al. [31] experimentally studied the effect of the $\mathrm{pH}$ value of the $\mathrm{Al}_{2} \mathrm{O}_{3}$ nanoparticle in deionoized water. The nanofluid was prepared with a two-step method. The nanoparticles $\left(\mathrm{Al}_{2} \mathrm{O}_{3}\right)$ were deagglomerated by intensive ultrasonication after being mixed with a base fluid, and then the suspensions were homogenized by magnetic force agitation [31]. Xie et al. used a transient hot-wire technique to measure the thermal conductivity of the suspensions. Their study showed that the effective thermal conductivities of nanofluid increased with an increase in the volume fraction, but with a different slope for different $\mathrm{pH}$ values. Their results presented in Fig. 14 indicate that the enhanced thermal conductivity ratio decreases with an increase in $\mathrm{pH}$ value.

There are other effects such as effect(s) of surfactants. Eastman et al. [5] used thioglycolic acid stabilizing agent and reported that the nanofluid samples which included the acidic agents showed improved enhancement compared with nonacid-containing nanofluids. Particle surface treatment was believed to have an impact on thermal conductivity of nanofluids.

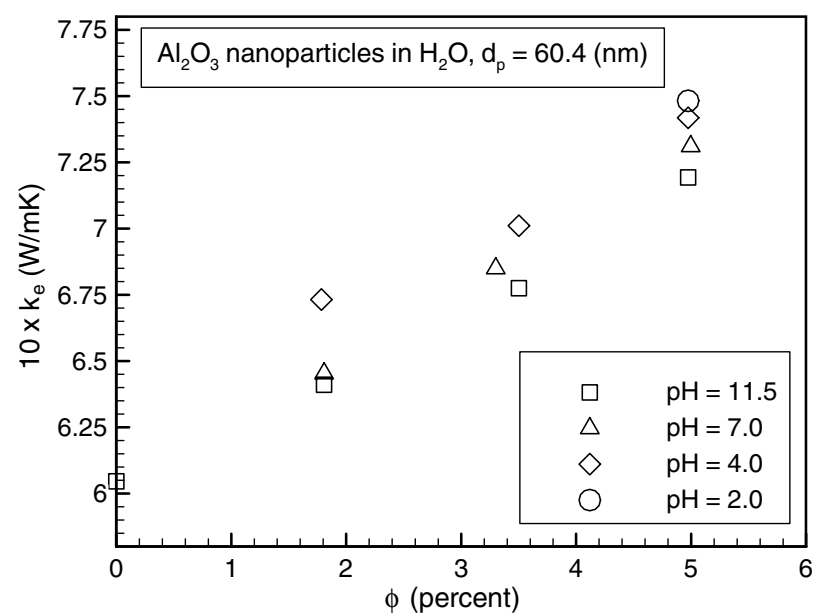

Fig. 14 Enhanced thermal conductivity ratio decreases with increasing $p \mathrm{H}$ value; data from $\mathrm{Xie}$ et al. [31].

\section{Summary and Conclusions}

The effective thermal conductivity of stationary nanofluids is studied. A comprehensive review is conducted and the theoretical models and experimental investigations in the open literature are collected and discussed. Our review on theoretical models indicates that a clear understanding of the main mechanism(s) involved in thermal transport phenomena in nanofluids is not established yet.

A review of experimental studies clearly shows a relatively large chaos and randomness in the published data. This requires a careful, repeatable, systematic approach to thermal conductivity measurement and sample preparation. Only through collecting reliable data can a better understanding of the phenomena in nanofluids be possible. The following summarizes our observations:

1) The data show a large scatter; however, they show some level of thermal conductivity enhancement when compared with existing models such as Maxwell's [14].

2) Assuming isothermal nanoparticles, we have developed upper/ lower bounds for steady-state conduction in stationary nanofluids and compared these bounds with the data. The comparison indicates that the data lie between the bounds of conduction.

3) All of the tests were performed at room temperature, except for Das et al. [6] and Patel et al. [6] in which the effect of temperature on thermal conductivity enhancement was investigated.

4) Except for $\mathrm{Cu}-\mathrm{EG}$ nanofluids used by Eastman et al. [5], where a single-step process was used, the rest of the nanofluids were made using a two-step method.

5) There is no common trend in thermal conductivity enhancement with increasing the volume fraction. From conduction-based models, it is intuitively expected to see a linear increase in thermal conductivity with volume fraction. However, several groups reported a nonlinear trend; see Murshed et al. [34], Hong et al. [35], Wang et al. [36], and Kwak and Kim [37] (Table 2).

6) The effect of nanoparticle size on the effective conductivity is not consistent with data from different groups. The data of Wang et al. [32] and Xie et al. [31] show that there are no direct correlations between particle size and effective conductivity enhancement.

7) The thermal conductivity of nanoparticles (bulk value) does not seem to have a direct impact on conductivity enhancement; see the data of Wang et al. [32] and Xie et al. [31]. On the other hand, Eastman et al. [5] reported higher thermal conductivity particles result in higher thermal enhancement.

\section{Acknowledgments}

The authors gratefully acknowledge the financial support of the Centre for Microelectronics Assembly and Packaging and the Natural Sciences and Engineering Research Council of Canada. 


\section{References}

[1] Choi, S. U. S., "Enhancing Thermal Conductivity of Fluids with Nanoparticles," Development and Applications of Non-Newtonian Flows, edited by D. A. Siginer and H. P. Wang, American Society of Mechanical Engineers, New York, 1995, pp. 99-105.

[2] Masuda, H., Ebata, A., Teramae, K., and Hishinuma, N., "Alteration of Thermal Conductivity and Viscosity of Liquid by Dispersing UltraFine Particles (Dispersion and $\mathrm{Al}_{2} \mathrm{O}_{3}, \mathrm{SiO}_{2}$, and $\mathrm{TiO}_{2}$ Ultra-Fine Particles)," Netsu Bussei, Vol. 7, No. 4, 1993, pp. 227-233.

[3] Artus, R. G. C., "Measurements of the Novel Thermal Conduction of a Porphoritic Heat Sink Paste," IEEE Transactions on Components, Packaging, and Manufacturing, Part B, Vol. 19, No. 3, 1996, pp. 601604.

[4] Eastman, J. A., Choi, S. U. S., Li, S., Thompson, L. J., and Lee, S., "Enhanced Thermal Conductivity Through the Development of Nanofluids," Material Research Society Symposia Proceedings, Vol. 457, Dec. 1997, pp. 3-11.

[5] Eastman, J. A., Choi, S. U. S., Li, S., Yu, W., and Thompson, L. J., "Anomalously Increased Effective Thermal Conductivities of Ethylene Glycol-Based Nanofluids Containing Copper Nanoparticles," Applied Physics Letters, Vol. 78, No. 6, 2001, pp. 718-720.

[6] Das, S. K., Putra, N., Thiesen, P., and Roetzel, W., "Temperature Dependence of Thermal Conductivity Enhancement for Nanofluids," Journal of Heat Transfer, Vol. 125, No. 4, 2003, pp. 567-574.

[7] Hu, Z. S., and Dong, J. X., "Study on Antiwear and Reducing Friction Factor Additive of Nanometer Titanium Oxide," Wear, Vol. 216, 1998, pp. 92-96.

[8] You, S. M., Kim, J. H., and Kim, K. H., "Effect of Nano-Particles on Critical Heat Flux of Water in Pool Boiling Heat Transfer," Applied Physics Letters, Vol. 83, 2003, pp. 3374-3376.

[9] Choi, S. U. S., Zhang, Z. G., Lockwood, F. E., and Grulke, E. A., "Anomalous Thermal Conductivity Enhancement in Nanotube Suspensions," Applied Physics Letters, Vol. 79, No. 14, 2001, pp. 2252-2254.

[10] Pak, B. C., and Cho, Y. I., "Hydrodynamic and Heat Transfer Study of Dispersed Fluids with Submicron Metallic Oxide Particles," Journal of Experimental Heat Transfer, Vol. 11, No. 2, 1998, pp. 151-170.

[11] Eastman, J. A., Phillpot, S. R., Choi, S. U. S., and Keblinski, P., "Thermal Transport in Nanofluids," Annual Review of Materials Research, Vol. 34, 2004, pp. 219-246.

[12] Yatsuya, S., Tsukasaki, Y., Mihama, K., and Uyeda, R., "Preparation of Extremely Fine Particles by Vacuum Evaporation onto a Running Oil Substrate," Journal of Crystal Growth, Vol. 45, No. 1, 1978, pp. 490495.

[13] Goodson, K. E., Flik, M. I., Su, L. T., and Antoniadis, D. A., "Prediction and Measurement of the Thermal Conductivity of Amorphous Dielectric Layers," Journal of Heat Transfer, Vol. 116, No. 2, 1994, pp. 317-324.

[14] Maxwell, J. C., A Treatise on Electricity and Magnetism, Clarendon, Oxford, England, U.K., 1873.

[15] Hamilton, R. L., and Crosser, O. K., "Thermal Conductivity of Heterogeneous Two-Component Systems," Industrial \& Engineering Chemistry Fundamentals, Vol. 1, No. 3, 1962, pp. 187-191.

[16] Wang, J., Chen, G., and Zhang, Z., "Model of Nanofluids Thermal Conductivity," Paper 2005-72797, 2005.

[17] Felske, J., "Effective Thermal Conductivity of Composite Spheres in a Continuous Medium with Contact Resistance," International Journal of Heat and Mass Transfer, Vol. 47, No. 14-16, 2004, pp. 3453-3461.

[18] Yu, W., and Choi, S. U. S., "The Role of Interfacial Layers in the Enhanced Thermal Conductivity of Nanofluids: A Renovated Maxwell Model," Journal of Nanoparticle Research, Vol. 5, No. 1-2, 2003, pp. 167-171.

[19] Yu, W., and Choi, S. U. S., "The Role of Interfacial Layers in the Enhanced Thermal Conductivity of Nanofluids: A Renovated Hamilton-Crosser Model," Journal of Nanoparticle Research, Vol. 6, No. 4, 2004, pp. 355-361.

[20] Uhlenbeck, G. E., and Ornstein, L. S., "On the Theory of the Brownian Motion," Physical Review, Vol. 36, 1930
[21] Xuan, Y., Li, Q., and Hu, W., "Aggregation Structure and Thermal Conductivity of Nanofluids," AIChE Journal, Vol. 49, No. 4, 2003 , pp. 1038-1043.

[22] Jang, S. P., and Choi, S. U. S., "Role of Brownian Motion in the Enhanced Thermal Conductivity of Nanofluids," Applied Physics Letters, Vol. 84, No. 21, 2004, pp. 4316-4318.

[23] Kumar, D. H., Patel, H. E., Rajeev Kumar, V. R., Sundarajan, T., Pradeep, T., and Das, S. K., "Model for Heat Conduction in Nanofluids," Physical Review Letters, Vol. 93, No. 14, 2004, pp. 144301-144305.

[24] Keblinski, P., Phillpot, S. R., Choi, S. U. S., and Eastman, J. A., "Mechanisms of Heat Flow in Suspensions of Nano-Sized Particles (Nanofluids)," International Journal of Heat and Mass Transfer, Vol. 45, 2002, pp. 855-863.

[25] Prasher, R., "Brownian-Motion-Based Convective Model for the Thermal Conductivity of Nanofluids," Proceedings of the American Society of Mechanical Engineers Summer Heat Transfer Conference, American Society of Mechanical Engineers, New York, 2005.

[26] Koo, J., and Kleinstreuer, C., "A New Thermal Conductivity Model for Nanofluids," Journal of Nanoparticle Research, Vol. 6, No. 6, 2005, pp. 577-588.

[27] Prasher, R., "Thermal Transport due to Phonons in Random NanoParticulate Media in the Multiple and Dependent (Correlated) Elastic Scattering Regime," Journal of Heat Transfer, Vol. 128, No. 7, 2006, pp. 627-637.

[28] Elrod, H. G., "Two Simple Theorems for Establishing Bounds on the Total Heat Flow in Steady-State Heat-Conduction Problems with Convective Boundary Conditions," Journal of Heat Transfer, Vol. 96, No. 1, 1994, pp. 65-70.

[29] Wang, X., Xu, X., and Choi, S. U. S., "Thermal Conductivity of Nanoparticle-Fluid Mixture," Journal of Thermophysics and Heat Transfer, Vol. 13, No. 4, 1999, pp. 474-480.

[30] Lee, S., Choi, S. U. S., Li, S., and Eastman, J. A., "Measuring Thermal Conductivity of Fluids Containing Oxide Nanoparticles," Journal of Heat Transfer, Vol. 121, No. 2, 1999, pp. 280-289.

[31] Xie, H., Wang, J., Xi, T., Liu, Y., and Ai, F., "Thermal Conductivity Enhancement of Suspensions Containing Nanosized Alumina Particles," Journal of Applied Physics, Vol. 91, No. 7, 2002, pp. $4568-4572$.

[32] Wang, Y., Fisher, T. S., Davidson, J. L., and Jiang, L., "Thermal Conductivity of Nanoparticle Suspensions," 8th AIAA and ASME Joint Thermophysics and Heat Transfer Conference, American Society of Mechanical Engineers, New York, 2002.

[33] Patel, H. E., Das, S. K., Sundararajan, T., Sreekumaran, A., George, B., and Pradeep, T., "Thermal Conductivity of Naked and Monolayer Protected Metal Nanoparticle Based Nanofluids: Manifestation of Anomalous Enhancement and Chemical Effects," Applied Physics Letters, Vol. 83, No. 14, 2003, pp. 2931-2933.

[34] Murshed, S. M. S., Leong, K. C., and Yang, C., "Enhanced Thermal Conductivity of $\mathrm{TiO}_{2}$-Water Based Nanofluids," International Journal of Thermal Sciences, Vol. 44, No. 44, 2005, pp. 367-373.

[35] Hong, T., Yang, H., and Choi, C. J., "Study of the Enhanced Thermal Conductivity of Fe Nanofluids," Journal of Applied Physics, Vol. 97, 2005, pp. 064311-1-064311-4.

[36] Wang, B., Zhou, L., and Peng, X., "A Fractal Model for Predicting the Effective Thermal Conductivity of Liquid with Suspension of Nanoparticles," International Journal of Heat and Mass Transfer, Vol. 46, July 2003, pp. 2665-2672.

[37] Kwak, K., and Kim, C., "Viscosity and Thermal Conductivity of Copper Oxide Nanofluid Dispersed in Ethylene Glycol," KoreaAustralia Rheology Journal, Vol. 17, No. 2, 2005, pp. 35-40.

[38] Nagasaka, Y., and Nagashima, A., "Absolute Measurement of the Thermal Conductivity of Electrically Conducting Liquids by Transient Hot-Wire Method," Journal of Physics E: Scientific Instruments, Vol. 14, No. 14, 1981, pp. 1435-1439.

[39] Czarnetzki, W., and Roetzel, W., "Temperature Oscillation Techniques for Simultaneous Measurement of Thermal Diffusivity and Conductivity," International Journal of Thermophysics, Vol. 16, No. 2, 1995, pp. 413-422. 